Para citar este artículo: Lopes, J. W., De Souza Nunes, P., \& Furtado Veloso, M. do S. (2019). Ciberativismo LGBT: uma análise das publicações da iniciativa \#VotelGBT (Brasil). Anuario Electrónico de Estudios en Comunicación Social "Disertaciones", 12(1), 112-127. Dol: http://dx.doi.org/10.12804/revistas.urosario.edu. co/disertaciones/a.6984

\title{
CIBERATIVISMO LGBT: UMA ANÁLISE DAS PUBLICAÇÕES DA INICIATIVA \#VOTELGBT (BRASIL)
}

\section{Cyberactivism LGBT: an Analysis of the \#VotelGBT Initiative Publications (Brazil) \\ Ciberactivismo LGBT: un análisis de las publicaciones de la iniciativa \#VotelGBT (Brasil)}

John Willian Lopes, Universidade Federal do Rio Grande do Norte (Brasil) johnwillianlopes@ufrn.edu.br

Patrícia de Souza Nunes, Universidade Federal do Rio Grande do Norte (Brasil) patricia.nunes.ufrn@gmail.com

Maria do Socorro Furtado Veloso, Universidade Federal do Rio Grande do Norte (Brasil) socorroveloso@uol.com.br

Recibido:

Aprobado:

\section{RESUMO}

Este artigo analisa os conteúdos produzidos pela campanha ciberativista \#VotelGBT, surgida durante o pleito eleitoral brasileiro de 2014, em redes de comunicação digital distribuída, e centrada no aumento da participação e representação política LGBT. O corpus é composto por publicações realizadas em página da rede social Facebook, durante os dois primeiros momentos de atuação da campanha (2014 e 2016). A partir da análise de conteúdo bardiniana, conclui-se que as principais intenções de comunicação empregadas voltaram-se para a sensibilização e 
convocação (chamada à ação) dos eleitores, refletindo a legitimidade das pautas e a importância do envolvimento com os processos institucionais de participação.

Palavras-chave: ciberativismo, Facebook, \#VotelGBT, Brasil.

\section{ABSTRACT}

This paper analyzes the content produced by the \#VotelGBT cyberactivist campaign, that emerged throughout the Brazilian election of 2014, in the digital communication networks distributed, aiming at increasing participation and political representation LGBT. The corpus is composed of publications carried out on the social network page Facebook, throughout the first two moments of the campaign (2014 and 2016). From the bardinian content analysis, we conclude that the main intentions of communication used were to raise awareness and convocation (call to action) of voters, reflecting the legitimacy of the agenda and the importance of involvement with the institutional processes of participation.

Keywords: Cyberactivism, Facebook, \#VoteıgBT, Brazil.

\section{RESUMEN}

Este artículo analiza los contenidos producidos por la campaña ciberactivista \#VoteıGBT, surgida durante el período electoral brasileño de 2014, en redes de comunicación digital distribuida, y centrada en el aumento de la participación y representación política LGBT. El corpus se compone de publicaciones realizadas en página de la red social Facebook, durante los dos primeros momentos de actuación de la campaña (2014 y 2016). A partir del análisis de contenido bardiniano, se concluye que las principales intenciones de comunicación empleadas se volvieron a la sensibilización y convocatoria (llamada a la acción) de los electores, reflejando la legitimidad de las pautas y la importancia del compromiso en los procesos institucionales de participación.

Palabras clave: ciberactivismo, Facebook, \#VotelgBt, Brasil.

O movimento coletivo por direitos LGBT completará, ainda nesta década, meio século desde que irrompeu para o mundo como uma força substantiva de luta política, social e cultural. Ao longo desse tempo, o processo de politização das identidades de gênero e orientações sexuais envolveu diversos sujeitos, coletivos, organizações e instituições da sociedade que nem sempre foram consonantes em suas perspectivas. Como terreno político (ou seja, que não se restringe à intimidade, mas também que contempla uma amplitude de vivências compartilhadas), a sexualidade atrai "múltiplas vozes discordantes, tentando se sobrepor umas às outras, em embates que não se 


\section{DISERTACIONES}

ESTUDIOS

Comunicación y dispositivos móviles

ISSN: 1856-9536

Dol de la revista: $\mathrm{http}: / / \mathrm{dx}$.doi.org/10.12804/disertaciones

Volumen 12, Número 1 / Enero-junio 2019

Versión PDF para imprimir desde

http://revistas.urosario.edu.co/index.php/disertaciones

restringem às ruas, aos parlamentos ou aos tribunais, mas envolvem todas as áreas da vida social" (Simões \& Facchini, 2009, p. 12).

Entende-se que o movimento pelos direitos de pessoas LGBT foi e continua sendo lapidado por diferentes forças. Muitas dessas forças são expressas em expressões de discursos legitimadores que naturalizam um modelo dominante, com vistas a definir papéis sociais de homens e mulheres (Valcuende del Río, 2004). Embora esteja institucionalizado sob a sigla LGBT (Lésbicas, Gays, Bissexuais, Travestis, Transexuais e Intersexos), o movimento congrega diversas iniciativas, identidades e orientações que têm buscado demandas, agendas conjuntas e próprias de luta por direitos sociais e políticos, complexificando cada vez mais as formas de articulação, expressão e mobilização de significados.

Compreendendo a necessidade de consolidar novas frentes de reivindicação, o movimento buscou deslocar suas lutas também para o campo da disputa política institucional no Brasil. Foi nessa conjuntura que surgiu, no ano eleitoral de 2014, uma campanha da sociedade civil, de caráter suprapartidário, cujo objetivo principal foi aumentar a representatividade pró-LGBT dentro dos partidos políticos e nos poderes legislativos, visando ao desenvolvimento e implementação de políticas públicas direcionadas à população LGBT. Denominada de \#VoteLGBT, foi organizada por ativistas sociais e define-se também como um coletivo autogerido e não institucionalizado, dedicado às campanhas durantes os pleitos eleitorais e à contínua construção do debate acerca da temática da participação LGBT na política.

A \#VotelGBT irrompeu em redes de comunicação digital distribuída como uma iniciativa centrada no aumento da participação e representação política LGBT no Brasil. Na ocasião, lançou mão das possibilidades da internet através da criação de perfis em diferentes sites de redes sociais (Recuero, 2009) e de conteúdo -Facebook, Twitter, YouTube e Tumblr-. A opção por esses sites resulta da intenção dos organizadores acerca da iniciativa, que era torná-la conhecida da forma mais rápida possível, no curto espaço de tempo até as eleições daquele ano, com o mínimo de custos. Não se tinha, com precisão, noção do quão producente seria a entrada em cada uma dessas redes a partir de um perfil, ou seja, de quais usos se poderia fazer para somar e atender às expectativas.

Nesse processo, a página no Facebook acabou se tornando central nas ações da campanha, embora as demais continuassem sendo atualizadas em 2014. No segundo momento, em 2016, as páginas no Twitter, YouTube e Tumblr foram descontinuadas e isso está relacionado a dois aspectos importantes: primeiro, a familiaridade dos integrantes com os mecanismos do Facebook, ou seja, a experiência pessoal prévia deles com as suas funcionalidades sinaliza ter sido determinante na escolha desse site de rede social; segundo, a falta de pessoal necessário para o gerenciamento e produção de conteúdo dos demais perfis.

Considerando tais aspectos, este trabalho tem como objetivo central analisar o conteúdo das publicações realizadas por essa iniciativa, caracterizada como ciberativista, em sua página no site de rede social Facebook, nos dois primeiros anos eleitorais em que atuou (2014 e 2016), verificando os temas presentes e predominantes, de modo a identificar as intenções das comunicações. Para tanto, emprega-se como técnica de análise dos dados a análise de conteúdo (Ac) proposta por Bardin (1977).

Recorda-se, ainda, que os dados ora apresentados constituem um corpus mais expressivo, a partir do qual discute-se como a emergência de práticas ciberativistas centradas na representação política LGBT contribui para a consolidação do movimento, bem como para o aprofundamento da democracia brasileira (Lopes, 2018).

\section{4}




\section{DISERTACIONES}

ESTUDIOS

\section{Ciberativismo: breve olhar sobre o conceito}

No contexto social contemporâneo, a partir de fins do século passado, o desenvolvimento das novas tecnologias de informação e comunicação elevou as possibilidades de acesso dos atores sociais de uso de macro e microtecnologias da comunicação, no instante em que as tecnologias penetravam cada vez mais o cotidiano. Segundo Vizer (2007, p. 42), elas "têm a virtude de gerar novos espaços e tempos, novos dispositivos... que terminam tecendo novas ecologias em rede da sociedade da informação". No campo dos movimentos sociais (Gohn, 1995, 2011), a difusão paralela ao redor do mundo das mídias sociais digitais e da agitação social tem suscitado questionamentos sobre a relação delas no desenvolvimento de protestos, dissidências e outras formas de política contenciosa nas redes de comunicação digital distribuída. Uma das discussões trata da nova estrutura de organização social, as comunidades virtuais (Rheingold, 2004), que rompeu com o ativismo social que vinha sendo realizado no campo comunicacional (Malini \& Antoun, 2013).

Assim, com a formação dessas comunidades emerge o ciberativismo, em meados da década de 1980, no período da pré-web (Wray, 1998). Desde então, procurou-se compreender, conceituar e tipificar as práticas ciberativistas, considerando os contextos em que surgiram e se realizaram. No campo comunicacional, o tema do ciberativismo no Brasil parece que vem se mantendo estável dentro do escopo geral, com certa regularidade no número de trabalhos publicados (Amaral \& Montardo, 2010, 2011, 2012). Já as compreensões do que seja o ciberativismo são plurais, os esforços para conceituá-lo e as tentativas de categorização se diversificam, como os próprios termos preferidos pelos autores - ativismo digital, ativismo online, ativismo na internet, ativismo em rede, cibermilitância, net-ativismo, webativismo.

A relação entre as redes de comunicação digital distribuída e as diversas iniciativas ciberativistas pode acontecer de diferentes maneiras, como por meio da formação de redes de indignação (Castells, 2012) resultantes de demandas e deficiências sociais, políticas, econômicas, culturais e psicológicas, que são proporcionadas pela "consonância cognitiva" entre indivíduos emissores-receptores da mensagem e por um canal (processo) de comunicação eficaz. De forma contrária a essa formulação, há quem considere essas redes ou "ondas de indignação" inapropriadas para configurar o discurso e espaço públicos, devido ao caráter fluido e à volatilidade delas, como sustenta Byung-Chul Han (2014). Para o autor, embora sejam eficientes para mobilizar e reunir a atenção, essas ondas não podem ser controladas, são efêmeras e amorfas, não têm estabilidade, continuidade e dispersam-se da forma que surgem. Essa indignação digital, assevera, não constitui um "nós" estável que aponte para uma estrutura de cuidado conjunto da sociedade, "é um estado afetivo que não desenvolve nenhuma força poderosa de ação" (Han, 2014, p. 22, tradução nossa), ou seja, a sociedade da indignação não engendra nenhum futuro. Distantes, essas compreensões focalizam e ilustram dimensões diferentes em relação às práticas comunicacionais, sociopolíticas, culturais, econômicas e psicológicas em e nas redes de comunicação digital distribuída.

Uma outra discussão que coloca em estado de relatividade os processos, resultados e as práticas comunicacionais engendradas por iniciativas ciberativistas em e nas redes de comunicação digital distribuída, refere-se à noção de "filtro-bolha", apontada por Pariser (2012). Segundo o autor, esses filtros, estruturados por algoritmos, são responsáveis por examinar os gostos, as ações, as relações e fazer extrapolações. Assim, criam um universo de informações exclusivo para cada pessoa, alterando a forma como se percebe as ideias e informações. 


\section{DISERTACIONES}

ESTUDIOS

Alguns autores se referem ao ciberativismo como toda ação realizada online por usuários, que visa encaminhar os esforços coletivos para a mudança social (Earl et al., 2010); como a utilização da internet em ações por movimentos politicamente motivados (Vegh, 2003; Denning, 2001), visando ao alcance de metas tradicionais ou o embate com as injustiças que ocorrem na própria rede (Rigitano, 2005); como conjunto de práticas em defesa de causas políticas, socioambientais, sociotecnológicas e culturais que são realizadas nas redes cibernéticas, em especial na internet (Silveira, 2010); como movimentos sociais interconectados em rede (Langman \& Morris, 2002); como estratégias de alteração da agenda pública mediante difusão de significados e propagação pelos meios de comunicação e publicação eletrônica pessoal (Ugarte, 2007); como biopolítica da rede (Malini \& Antoun, 2013); como produção incessante e imanente do comum nas e pelas redes, ou biopolítica digital (Condorelli, 2015); como net-ativismo, que se articula como maximização de possibilidades de autonomia, processos de sustentabilidade e de criatividade (Di Felice, 2013).

Essas sínteses - deixando de fora outros elementos das formulações dos autores- ajudam a estruturar uma definição cara a este trabalho, que compreende o ciberativismo como múltiplas práticas de sujeitos coletivos e individuais operadas nas redes de comunicação digital distribuída que objetivam a defesa de determinadas causas para promover mudanças na sociedade que favoreçam a vivência comum, recorrendo à circulação de ideias e de possibilidades técnicas (ferramentas) para engendrar formas de participação e intervenção.

\section{Elementos metodológicos}

A análise correspondeu às postagens realizadas em dois períodos: de 27 de agosto a 8 de outubro de 2014 (da primeira à última postagem), e de 19 de abril a 5 de outubro de 2016 (da primeira postagem até três dias após a data do primeiro turno). Apoiando-se na observação direta, utilizou-se a ferramenta FireShot (uma extensão para navegadores) para a colheita dos dados, para a cópia via captura de tela das publicações da página no Facebook ${ }^{1}$ - a colheita foi realizada em 2016, na atividade da iniciativa-.

Como técnica de análise, optou-se pela análise de conteúdo (Ac), "que utiliza procedimentos sistemáticos e objetivos de descrição do conteúdo das mensagens" (Bardin, 1977, p. 38). A Ac objetiva a inferência de conhecimentos relativos às condições de produção (ou de recepção) das mensagens a partir de indicadores, quantitativos ou não. A inferência refere-se à dedução de forma lógica, sendo considerada como procedimento intermediário entre a descrição (enumeração das características do texto) e a interpretação (significação conferida a essas características).

A análise conteudista bardiniana é constituída por três fases: pré-análise, correspondente à fase de organização dos materiais para a análise seguindo as regras da exaustividade (considera todos os elementos do corpus), da representatividade (define uma amostra que represente o universo inicial), da homogeneidade (os dados devem se referir ao mesmo tema e terem sido obtidos com as mesmas técnicas e indivíduos semelhantes), da pertinência (os documentos devem corresponder aos objetivos da pesquisa); exploração do material coletado, corresponde às operações de codificação, conforme os parâmetros estabelecidos (unidades de registro, formas de enumeração e categorização); tratamento dos resultados, corresponde à tabulação e apresentação deles em quadros, figuras, modelos, tabelas de modo a condensá-los para que destaquem as informações fornecidas para a análise.

1 \#VotelgBt. (2016). Em Facebook (Fan page). Recuperado de https://www.facebook.com/votelgbt 
As publicações foram organizadas em ordem cronológica, com informações sobre a data de publicação, interações (curtidas, compartilhamentos, comentários), imagem de cada uma, o formato do conteúdo (texto, vídeo, imagem, hiperlink) e informações de acesso. Os resultados foram agrupados de modo a constituírem tipologias de conteúdo.

Interessa deslindar dois aspectos que se relacionam com a adequação para a análise de conteúdo digital: primeiro, foram consideradas, para a constituição do corpus, as mensagens veiculadas na timeline da página da campanha \#VotelGBT, enquadradas como "publicações da página" pelos próprios mecanismos do Facebook, sendo que notificações de atualizações das informações da página ou mesmo publicações de terceiros não foram contempladas; segundo, os formatos dos conteúdos possíveis nas publicações podem ser utilizados separados ou combinados. Assim, formatos diferentes em uma mesma publicação (texto escrito e imagem, por exemplo) podem implicar diferentes enunciados, que podem eventualmente dificultar uma categorização mais precisa. Desse modo, considerouse que a diversidade e enunciados não resulta, necessariamente, da presença de mais de um formato de conteúdo numa publicação, ou seja, uma imagem - por exemplo- pode conter mais de um enunciado. Em vista disso, considerou-se a publicação como um todo, em que verifica-se a predominância de intenção da comunicação, resultante da convergência de diferentes enunciados.

\section{Resultados e discussões}

Considerando os aspectos apontados, chegou-se a uma categorização na qual expressa-se os tipos de conteúdos que constituem as publicações realizadas pela iniciativa \#VotelGBt nos anos de 2014 e 2016. Durante o período da observação da página no Facebook, documentou-se 164 publicações (79 referentes a 2014 e 85 a 2016), que, utilizando a frequência como regra de enumeração (Bardin, 1977), foram agrupadas em quatro categorias temáticas: 'sensibilização do eleitor', 'repercussão na imprensa', 'chamada à ação' e 'informativo'. 
Tabela 1. Categorização do conteúdo das publicações da página \#Votelgbt

(2014 e 2016 juntos)

\begin{tabular}{|c|c|c|c|}
\hline Tipo & Nº de publicações & Subtipo & No de publicações \\
\hline \multirow{5}{*}{ Sensibilização do eleitor } & \multirow{5}{*}{69} & Explicação do sistema político-eleitoral & 7 \\
\hline & & Apelo à participação de personagens (depoimentos) & 27 \\
\hline & & Apelo ao resgate histórico & 2 \\
\hline & & Apelo ao engajamento & 27 \\
\hline & & Apelo ao contexto imediato & 6 \\
\hline \multirow{2}{*}{$\begin{array}{l}\text { Repercussão na } \\
\text { imprensa }\end{array}$} & \multirow{2}{*}{23} & Notícia em jornal/portal & 15 \\
\hline & & Participação de organizadores em entrevistas & 8 \\
\hline \multirow{6}{*}{ Chamada à ação } & \multirow{6}{*}{44} & Participação no conteúdo da campanha & 14 \\
\hline & & Participação por demonstração de apoio & 8 \\
\hline & & Participação na organização (voluntariado) & 8 \\
\hline & & Participação em debates propostos & 3 \\
\hline & & Participação no acesso ao conteúdo & 10 \\
\hline & & Instrução de utilização das ferramentas & 1 \\
\hline \multirow{4}{*}{ Informativo } & \multirow{4}{*}{28} & Anúncio de ação da campanha & 13 \\
\hline & & Anúncio de feitos/resultados & 10 \\
\hline & & Explicação de aspectos operacionais internos & 3 \\
\hline & & Anúncio de ação de terceiros & 2 \\
\hline
\end{tabular}

Fonte: Lopes (2018).

Cada uma dessas categorias principais foi dividida em subunidades, de modo a proverem uma aproximação mais detalhada dos conteúdos das publicações, portanto das intenções presentes nelas. Assim, analisando o tabela, tem-se a seguinte configuração:

Sensibilização do eleitor: corresponde às publicações direcionadas para os eleitores na intenção de torná-los sensíveis em relação aos assuntos pertinentes abordados pela campanha \#VotelGBT, para, consequentemente, reagirem positivamente a eles -e aos objetivos da iniciativa-. Ao todo, 69 publicações constituíram essa categoria, sendo 25 de 2014 e 44 de 2016 -no último ano essa categoria correspondeu à maioria dos conteúdos publicados, enquanto que no primeiro foi a segunda com mais correspondentes-. 


\section{DISERTACIONES}

ESTUDIOS

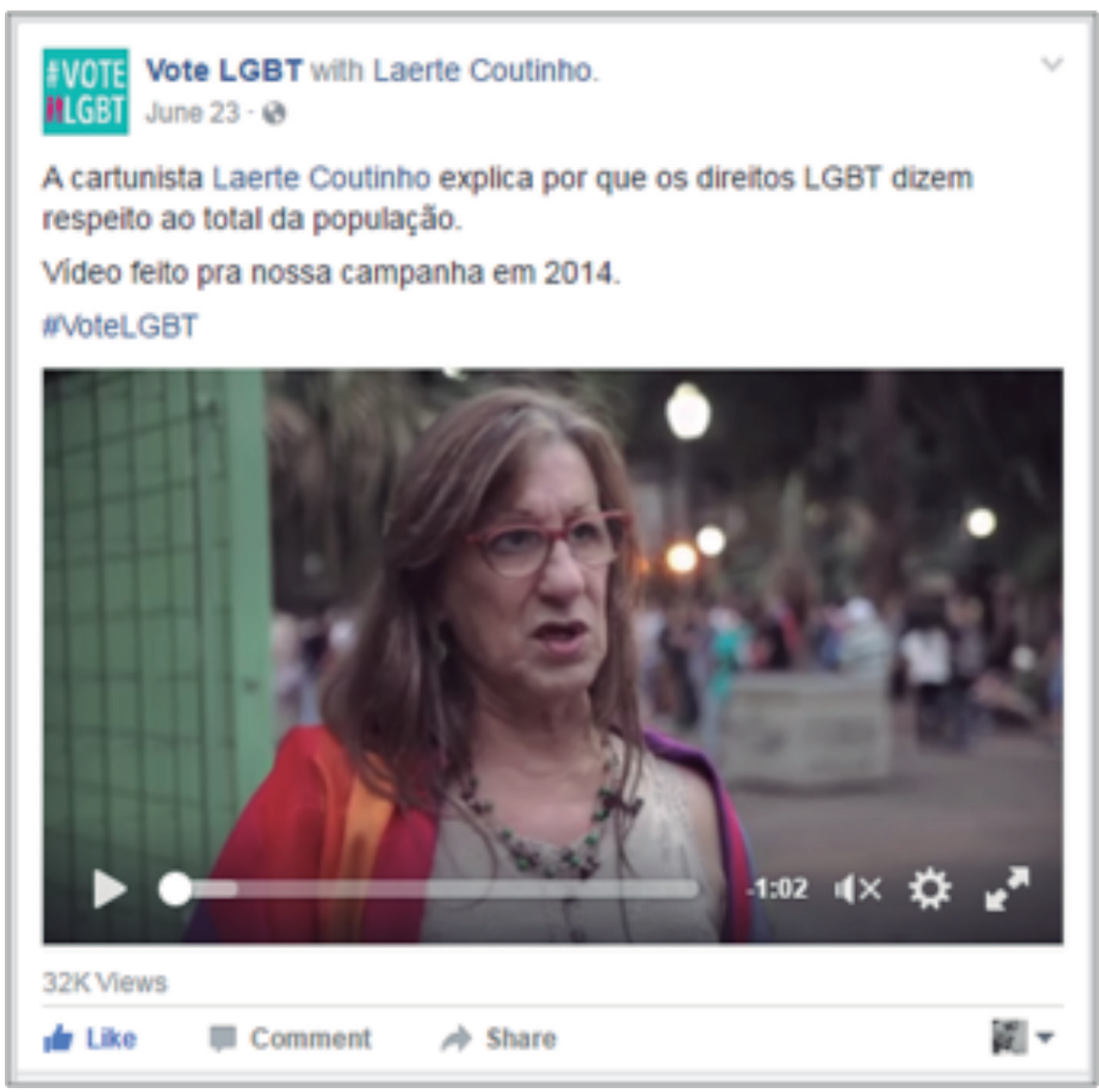

Figura 1. Exemplo de publicação (de 2016) categorizada como 'sensibilização do eleitor' Fonte: print screen elaborado por Lopes (2018).

Entende-se que a sensibilização dos eleitores ocorria de diferentes maneiras, expressas em conteúdos diversificados. Assim, estabeleceu-se cinco subcategorias: 'explicação do sistema político-eleitoral', 'apelo à participação de personagens (depoimentos)', 'apelo ao resgate histórico', 'apelo ao engajamento' e 'apelo ao contexto imediato'.

Na primeira, 'explicação do sistema político-eleitoral' (sete publicações), trata-se de esclarecer os eleitores acerca de aspectos relacionados ao sistema político brasileiro, como a função do Poder Legislativo, a importância dos partidos na política institucional, a necessidade de regularização da situação eleitoral para a participação nos pleitos, o recurso da anulação do voto e a não interferência nos resultados, e o direito de segredo sobre o voto; esse último ponto relaciona-se com a situação em que muitas pessoas se consideram apoiadoras, 'simpatizantes', pró-direitos de pessoas LGBT, porém demonstram também certo receio em expressarem-se como tal.

Na subcategoria 'apelo à participação de personagens (depoimentos)' (27 publicações) recorre-se à participação de diferentes pessoas que, através de depoimentos em vídeos, falam sobre questões diversas que envolvem a temática LGBT, como a vulnerabilidade social (violência, educação), falta de representatividade política e a importância de se votar em candidaturas pró-LGBT, a diversidade de atores políticos dentro do movimento, o respeito à 
diferença. Dentre os participantes dos vídeos estão eleitores, militantes, jornalistas e artistas, alguns dos quais com projeção, como a cartunista Laerte - ver figura 1-, a cantora Tiê, a jornalista Nana Caetano, as cantoras e apresentadoras Candy Mel e Ellen Oléria.

Na subcategoria 'apelo ao resgate histórico' (duas publicações), busca-se sensibilizar o eleitor através da retomada de fatos históricos relacionados ao movimento LGBT, especificamente os acontecimentos de junho de 1969, em Nova Iorque, e a militância do vereador homossexual de São Francisco, Harvey Milk - ver capítulo dois-; as publicações com esse tipo de conteúdo foram realizadas no contexto do Dia do Orgulho LGBT. Na subcategoria 'apelo ao engajamento' (27 publicações), tenciona-se a adesão dos eleitores não só à campanha em si, mas às pautas apresentadas que já são, em certa medida, discutidas dentro do movimento. Encaixa-se aqui uma série de publicações criada, em 2016, com a intenção de apresentar várias motivações para se votar LGBT —\#20MotivosParaVotarLGBT-, abordando a importância da representatividade, a visibilização das candidaturas favoráveis, os direitos LGBT como direitos humanos, a violência descrente essa parcela da população, o voto como instrumento de afirmação e de protesto, a educação e a inserção da discussão sobre questões de gênero e sexualidade, a saúde e o tratamento digno e de qualidade.

Por fim, a última subcategoria refere-se ao "apelo ao contexto imediato" (seis publicações), na qual empregase acontecimentos recentes - de cada ano- relacionando-os com os temas e as pautas, de modo a enquadrá-los na realidade cotidiana à qual os eleitores estão próximos - ou podem se aproximar-. Uma publicação de 2016, por exemplo, abordava o Massacre de Orlando, um atentado ocorrido em 12 de junho desse ano contra os frequentadores de uma boate LGBT -a Pulse-, e nela prestou-se solidariedade ao ocorrido chamando atenção para o fato de que "às vezes, o discurso de ódio usa armas de fogo", não apenas nos Estados Unidos, mas no Brasil e em partes do mundo.

Repercussão na imprensa: corresponde às publicações cuja intenção é de registrar a inserção da campanha \#VotelgBt nos assuntos tratados pelos meios de comunicação, seja em veículos tradicionais ou não, de modo a demonstrar, em certa medida, que a iniciativa ganhava relevância e chamava a atenção da mídia. Foram realizadas 23 publicações, sendo seis em 2014 e 17 em 2016. 


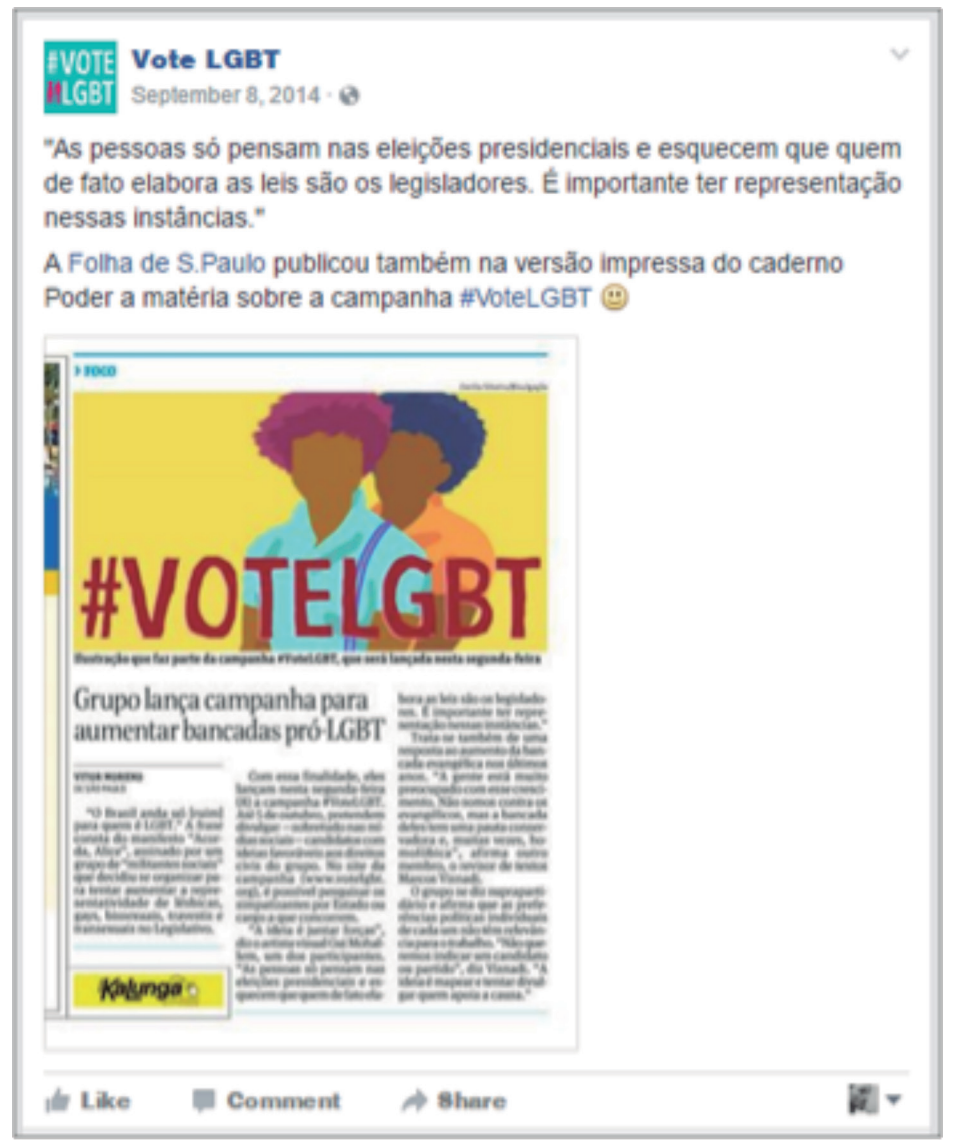

Figura 2. Exemplo de publicação (de 2014) categorizada como 'repercussão na imprensa' Fonte: print screen elaborado por Lopes (2018).

Buscando compreender como ocorria tal inserção, chegou-se a duas subcategorias de tipos de conteúdos: 'notícia em jornal/portal' e 'participação de organizadores em entrevistas'.

Em 'notícia em jornal/portal' (15 publicações), repercute-se textos jornalísticos que abordam diretamente a campanha ou aspectos relacionados a ela, como o seu lançamento em 2014, a menção da importância de iniciativas, como a \#VotelgBt, que buscam novas configurações no cenário político, a repercussão dos resultados das pesquisas realizadas na Caminhada de Mulheres Lésbicas e Bissexuais e na Parada do Orgulho LGBT, em 2016, na cidade de São Paulo. Dentre os veículos que publicaram notícias estão o jornal Folha de São Paulo -ver figura 2-, o El País Brasil, BandNews tv, HuffPost Brasil e BuzzFeed Brasil.

A subcategoria 'participação de organizadores em entrevistas' (oito publicações), refere-se à participação direta de integrantes da iniciativa em conteúdos jornalísticos ou informativos através da concessão de entrevistas, seja via textual escrita, vídeo ou áudio. Nessas participações, os integrantes buscavam apresentar a iniciativa e explicar a sua pertinência frente as questões relacionadas às pautas LGBT e de direitos humanos e à política. As 
entrevistas foram concedidas a canais no YouTube, como o Canal das Bee, Chá das Cinco e Canal da Shana, ao site Internet Lab, à Revista Trip e ao programa de podcast Lado Bi (no portal voL).

Chamada à ação: corresponde às publicações que intencionam propor aos eleitores a adesão a determinados posicionamentos voltados para a ação -e resposta- junto à iniciativa \#VotelgBt. Por essa via, recorre-se a uma perspectiva convocatória da comunicação, com vista a incitar os eleitores à participação imediata, ou seja, para que eles expressem determinadas atitudes que são interessantes para os objetivos da iniciativa. 0 número de publicações dessa categoria é de 44, sendo 31 referentes a 2014 e 13 a 2016.

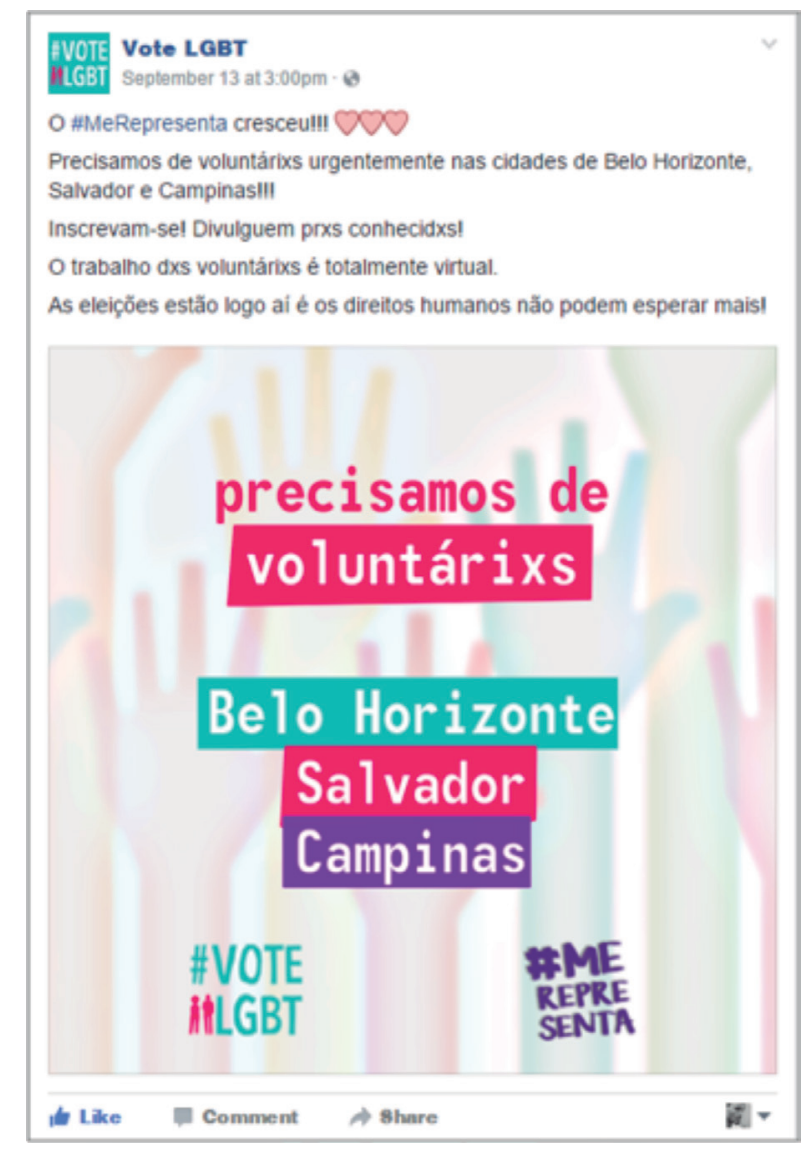

Figura 3. Exemplo de publicação (de 2016) categorizada como 'chamada à ação' Fonte: print screen elaborado por Lopes (2018).

Voltada para os eleitores, a chamada à ação realiza-se de diferentes maneiras, divididas em cinco subcategorias: 'participação no conteúdo da campanha', 'participação por demonstração de apoio', 'participação na organização (voluntariado)', 'participação em debates propostos' e 'instrução de utilização das ferramentas'.

Na subcategoria 'participação no conteúdo da campanha' (14 publicações) convoca-se os eleitores para colaborarem através do envio de conteúdos diversos, como indicações de candidaturas pró-LGBT e o envio de imagens 


\section{DISERTACIONES}

ESTUDIOS

Comunicación y dispositivos móviles

ISSN: 1856-9536

Dol de la revista: http://dx.doi.org/10.12804/disertaciones

Volumen 12, Número 1 / Enero-junio 2019

Versión PDF para imprimir desde

http://revistas.urosario.edu.co/index.php/disertaciones

dos eleitores, em 2014, com cartazes contendo a hashtag \#VotelGBT, para composição de um vídeo institucional. Na subcategoria 'participação por demonstração de apoio' (oito publicações), incita-se os eleitores a demonstrarem apoio à iniciativa, seja através do acompanhamento dela em outros sites de redes sociais ou do espalhamento dos conteúdos via compartilhamento das postagens, ou ainda através da contribuição com recursos financeiros - direcionados para arcar com as despesas das pesquisas, principalmente-.

A subcategoria 'participação na organização (voluntariado)' (oito publicações), refere-se, basicamente, às publicações voltadas para a chamada de voluntários, principalmente em 2016, ano em que duas pesquisas foram realizadas, e também quando aconteceram as buscas ativas por candidaturas pró-direitos humanos em algumas cidades -ver figura 3-. Algumas dessas publicações repercutiam notas com as chamadas publicadas antes na imprensa - como as notas publicadas na coluna da jornalista Mônica Bergamo, na Folha de São Paulo-. Outras publicações tensionaram o debate de assuntos propostos aos eleitores, como quais projetos de lei poderiam ser pertinentes para a garantia dos direitos de pessoas LGBT, Como a iniciativa deveria se comportar após o pleito de 2014 frente aos resultados e às experiências adquiridas, compondo assim a subcategoria 'participação em debates propostos' (três publicações).

Noutras publicações, busca-se a participação imediata dos eleitores por meio da apreciação dos conteúdos produzidos, ou seja, do acesso a eles. Assim, procurou-se sugerir aos eleitores que visitassem as ferramentas desenvolvidas (o site e a plataforma \#MeRepresenta), que realizassem o download da música tema da campanha em 2014 e assistissem o vídeo produzido a partir das imagens de outros eleitores expressando apoio à iniciativa. Tais publicações constituem a subcategoria 'participação no acesso ao conteúdo' (com dez publicações). A última subcategoria, 'instrução de utilização das ferramentas' (apenas uma publicação), diz respeito à formação dos eleitores para o uso das ferramentas desenvolvidas, no caso da plataforma \#MeRepresenta, de 2016, que são convocados a conhecerem suas as funcionalidades.

Informativo: corresponde às publicações que buscam anunciar aos eleitores as ações realizadas, ou seja, informá-los, em diferentes aspectos, acerca das atividades inerentes à campanha (internas) e relacionadas. Assim, 28 publicações constituíram essa categoria, sendo 17 referentes ao ano de 2014 e 11 ao ano de 2016. 


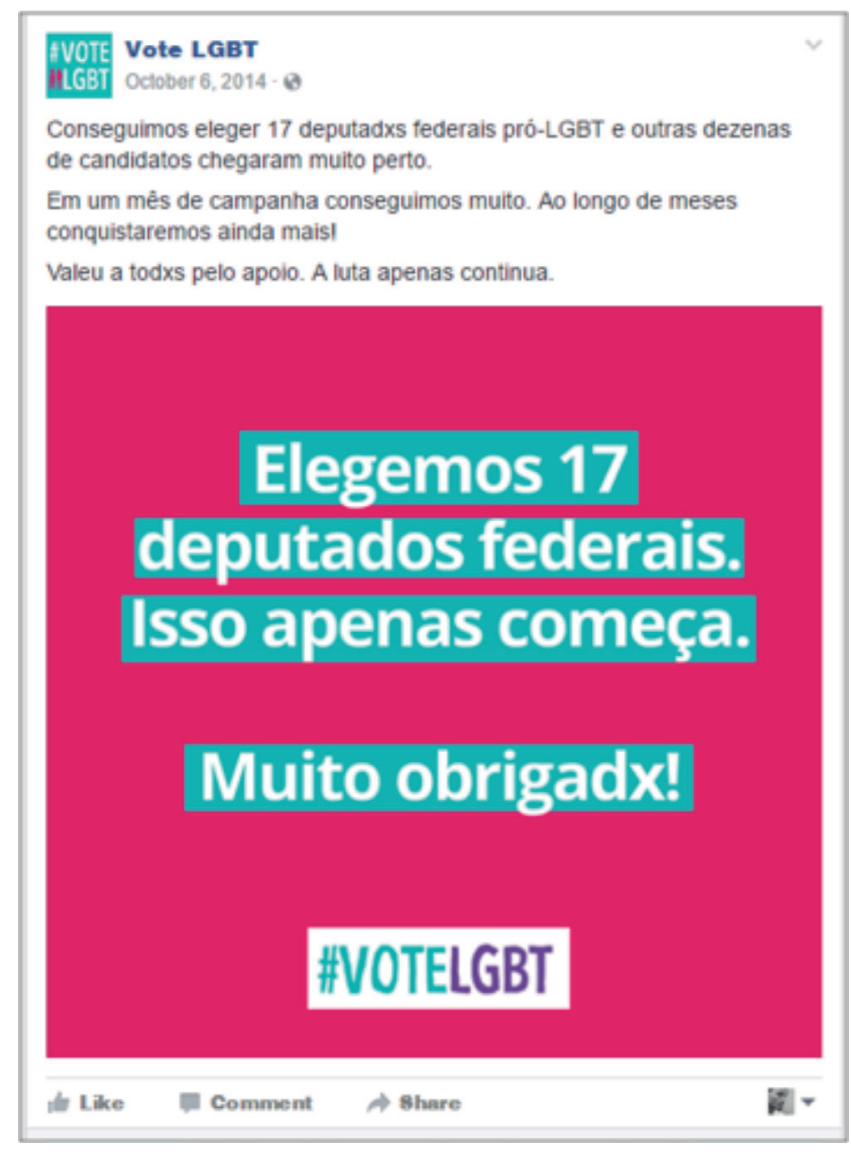

Figura 4. Exemplo de publicação (de 2014) categorizada como 'informativo' Fonte: print screen elaborado por Lopes (2018).

Compreende-se que os eleitores eram informados das atividades de diferentes formas, divididas aqui em quatro subcategorias: 'anúncio de ação da campanha', 'anúncio de feitos/resultados', 'explicação de aspectos operacionais internos' e 'anúncio de ação de terceiros'.

Em 'anúncio de ação da campanha' (13 publicações) informa-se os eleitores sobre pontos como o lançamento da campanha, em 2014, o trabalho de inclusão das candidaturas no site, a disponibilização das ferramentas sociais digitais (site e plataforma) aos eleitores e a participação de integrantes em atividades externas (eventos). Números relativos ao trabalho da iniciativa, como aumento na quantidade de seguidores nos sites de redes sociais, na quantidade de candidaturas visibilizadas, de eleitores cadastrados ou acessos às ferramentas, conclusão de ações como as pesquisas e o anúncio dos resultados delas, além do anúncio das candidaturas eleitas foram organizados na subcategoria 'anúncio de feitos/resultados' (dez publicações) -ver figura 4-.

Noutra subcategoria, 'explicação de aspectos operacionais internos' (três publicações), o eleitor é esclarecido sobre pontos relacionados ao funcionamento da iniciativa, como os critérios utilizados, em 2014, para a seleção e disponibilização das candidaturas, associados ao objetivo que era aumentar a representação política LGBT no 


\section{DISERTACIONES}

ESTUDIOS

Comunicación y dispositivos móviles

ISSN: 1856-9536

Dol de la revista: $\mathrm{http}: / / \mathrm{dx}$.doi.org/10.12804/disertaciones

Volumen 12, Número 1 / Enero-junio 2019

Versión PDF para imprimir desde

http://revistas.urosario.edu.co/index.php/disertaciones

Poder Legislativo. Um outro conteúdo interessante refere-se a uma publicação que convida o eleitor a entender a opção pela utilização do ' $x$ ' nos textos desse ano da campanha que, conforme argumenta-se, funciona como um tipo de protesto, através da língua, contra a heteronormatividade, o machismo e patriarcado. Por fim, em 'anúncio de ação de terceiros' (duas publicações), informa-se sobre atividades não realizadas pela iniciativa, mas que estão relacionadas dentro do contexto, como eventos com caráter de debate político sobre a temática dos direitos LGBT e a transmissão na mídia -como a realizada pelo portal Terra-.

A categorização dos conteúdos apresentada, quanto às intenções das comunicações, congrega publicações referentes aos dois primeiros momentos de atuação da iniciativa ciberativista \#VotelGBT, 2014 e 2016. Esse recurso de análise proporciona uma verificação de caráter abrangente, que permite realizar inferências alusivas a ambos os momentos. Com base nos dados referentes a cada categoria principal, verifica-se que: a de 'sensibilização do eleitor' foi aquela com mais publicações, e tal sensibilização estava centrada no apelo à participação de personagens diversos (eleitores, militantes, artistas, jornalistas), via depoimentos em vídeos, e no apelo ao engajamento de eleitores; a de 'chamada à ação' foi a segunda com mais publicações, tendo como principal intenção verificada a participação dos eleitores nos conteúdos da campanha, no acesso a tais conteúdos e na participação na organização, via voluntariado; a nomeada de 'informativo' foi a terceira, recorrendo principalmente ao anúncio de ações da campanha e dos feitos ou resultados alcançados nesses períodos. Já a subcategoria 'repercussão na imprensa' teve menos publicações, na qual recorria-se principalmente à repercussão de notícias acerca da atuação da campanha e à participação de seus integrantes em entrevistas.

Ao deslocar a análise da perspectiva abrangente para uma comparativa, entre os anos, percebe-se que os dados não são unânimes quanto às intenções de comunicação priorizadas. Ao se realizar uma comparação das categorias principais, tem-se: 'sensibilização do eleitor', com 25 em 2014 e 44 em 2016; 'repercussão na imprensa', seis em 2014 e 17 em 2016; 'chamada à ação', 31 em 2014 e 13 em 2016; e 'informativo', com 17 em 2014 e 11 em 2016. No ano de 2016, prioriza-se os conteúdos voltados para a sensibilização dos eleitores e para a repercussão da campanha na imprensa, ao passo que em 2014 destaca-se aqueles voltados para a chamada à ação por parte dos eleitores e para informá-los.

Essa configuração se dá em razão de que o primeiro ano de atuação da \#VotelGBT foi em 2014, portanto havia necessidade de esclarecer os eleitores sobre seus propósitos e funcionamentos, bem como apelava-se para sua colaboração, principalmente no tocante ao conteúdo da campanha, levando em consideração que a busca das candidaturas nesse momento era realizada pela organização, a partir da conferência das propostas apresentadas. Em 2016, por sua vez, houve um trabalho mais intenso de articulação com a imprensa, de veículos de comunicação a canais no YouTube. Isso contribuiu para que a iniciativa repercutisse na própria mídia, com jornalistas buscando novas pautas e encontrando novas plataformas coletivas empenhadas em discutir e fazer política de forma colaborativa. Contribuiu, também, para que os eleitores tomassem conhecimento sobre a iniciativa e como estava sendo proposta. 


\section{DISERTACIONES}

ESTUDIOS

\section{Considerações finais}

Neste artigo analisou-se o conteúdo das publicações (referentes a 2014 e 2016, juntos) realizadas pela iniciativa ciberativista \#VoteLGBT em sua página no site de rede social Facebook, verificando os temas presentes e predominantes de modo a identificar as intenções da comunicação.

Desse modo, conclui-se que ao longo da sua atuação nas redes de comunicação digital distribuída, nos anos de 2014 e 2016, a iniciativa \#VotelgBt adotou como principal estratégia comunicativa (intenções de comunicação) o emprego de recursos voltados para a sensibilização e convocação (chamada à ação) dos eleitores, através de conteúdos cujos significados refletiam a dimensão e legitimidade das suas pautas e dos debates que as cingem, ao mesmo tempo que demonstravam a importância do envolvimento, e de como fazê-lo, com os processos institucionais de participação - no caso as eleições - e seu reflexo no aumento substantivo da representação política LGBT no Brasil.

Importa salientar que, embora tenha-se focado aqui na análise das publicações, não se deve olvidar que elas compõem o conjunto de processos e ações comunicacionais do objeto investigado, a iniciativa ciberativista \#VotelgBt, que desenvolveu e disponibilizou para os usuários ferramentas sociais digitais importantes, como a plataforma \#MeRepresenta (Lopes, 2018). Assim, é possível entender que o que caracteriza tais publicações como ciberativistas não é o gesto publicador em si, mas as estratégias que o envolvem e os processos que o permeiam. Esses aspectos, por outro lado, se relacionam com uma problemática mais abrangente, em que se discute a pertinência da apropriação de sites de redes sociais, como o Facebook, e a criação de ferramentas alternativas pelas iniciativas, pois é pertinente considerar que as lógicas algorítmicas das redes digitais se baseiam nos próprios dados dos usuários para interferir nos seus hábitos de consumo de informações, sendo assim, nas próprias comunicações de iniciativas coletivas ciberativistas -e isso se relaciona com uma outra lógica, que é aquela instituída pelo capitalismo financeiro e midiático (Sodré, 2014)-.

Ao fim, sugere-se que pesquisas futuras possam investigar a atuação de outras iniciativas ciberativistas centradas na representação política, seja referente à temática LGBT ou a outros grupos sociais minorizados; que possam atentar para como esses fenômenos acontecem no Brasil e em outros países, as aproximações e os distanciamentos, a partir de uma abordagem comparativa.

\section{Referências}

1. Amaral, A. R., \& Montardo, S. P. (2010). Pesquisa em cibercultura e internet: estudo exploratório-comparativo da produção científica da área no Brasil e nos Estados Unidos. Conexão - Comunicação e Cultura, 9(18), 57-73.

2. Amaral, A. R., \& Montardo, S. P. (2011). Pesquisa em cibercultura: análise da produção brasileira da Intercom. Logos, 1(34), 102-116.

3. Amaral, A. R., \& Montardo, S. P. (setembro, 2012). Mapeamento temático da história da cibercultura no Brasil. XXXV Congresso Brasileiro de Ciências da Comunicação, Fortaleza, cE, Brasil.

4. Bardin, L. (1977). Análise de conteúdo. Lisboa: Edições 70. 


\section{DISERTACIONES}

ESTUDIOS

Comunicación y dispositivos móviles

ISSN: 1856-9536

Dol de la revista: http://dx.doi.org/10.12804/disertaciones

Volumen 12, Número 1 / Enero-junio 2019

Versión PDF para imprimir desde

http://revistas.urosario.edu.co/index.php/disertaciones

5. Castells, M. (2012). Redes de indignación y esperanza. Madrid: Alianza Editorial.

6. Condorelli, A. (2015). Da mobilização ciberativista a uma biopolítica das redes. II Net-Activism International Congress, São Paulo, Brasil.

7. Denning, D. E. (2001). Activism, hacktivism, and cyberterrorism: the internet as a tool for influencing foreign policy. En J. Arquilla \& D. Ronfeldt (Eds.), Networks and netwars: the future of terror, crime, and militancy (pp. 239-288). Santa Mónica: RAND Corporation.

8. Di Felice, M. (2013). Ser redes: o formismo digital dos movimentos net-ativistas. Matrizes, 7(2), 49-71.

9. Earl, J., Kimport, K., Prieto, G., Rush, C., \& Reynoso, K. (2010). Changing the world one webpage at a time: conceptualizing and explaining internet activism. Mobilization: an International Journal, 15(4), 425-446.

10. Gohn, M. G. (1995). História dos movimentos e lutas sociais: a construção da cidadania dos brasileiros. São Paulo: Edições Loyola.

11. Gohn, M. G. (2011). Movimentos sociais na contemporaneidade. Revista Brasileira de Educação, 16(47), 333-361.

12. Han, B. C. (2014). En el enjambre. Barcelona: Heder.

13. Langman, L., \& Morris, D. (2002). Internet mediation: a theory of alternative globalization movements. Proceedings do International Workshop on Community Informatics, Montreal, Canadá, 1.

14. Lopes, J. W. (2018). \#VotelgBt: ciberativismo por representação política no Brasil (Dissertação de mestrado, Universidade Federal do Rio Grande do Norte, Natal, RN, Brasil).

15. Malini, F., \& Antoun, H. (2013). A internet e a rua: ciberativismo e mobilização nas redes sociais. Porto Alegre: Sulina.

16. Pariser, E. (2012). O filtro invisível: o que a internet está escondendo de você. Rio de Janeiro: Zahar.

17. Recuero, R. (2009). Redes sociais na internet. Porto Alegre: Sulinas.

18. Rheingold, H. (2004). Multitudes inteligentes: la próxima revolución social. Barcelona: Editorial Gedisa.

19. Silveira, S. A. (2010). Ciberativismo, cultura hacker e individualismo colaborativo. Revista uSP, 86, 28-39.

20. Simões, J. A., \& Facchini, R. (2009). Na trilha do arco-íris: do movimiento homossexual ao LGBT. São Paulo: Perseu Abramo.

21. Sodré, M. (2014). A ciência do comum: notas para o método comunicacional. Petrópolis, RJ: Vozes.

22. Ugarte, D. (2007). El poder de las redes: manual ilustrado para personas, colectivos y empresas abocados al ciberactivismo. Madrid: Edição do Autor.

23. Valcuende del Río, J. M. (2004). Cuerpos, géneros y sexualidades: representaciones y prácticas sociales. Revista Crítica Jurídica, 23, 149-174.

24. Vegh, S. (2003). Classifying forms of online activism: the case of cyberprotests against the World Bank. En M. McCaughey \& M. D. Ayers (Eds.), Cyberactivism: online activism in theory and practice (pp. 71-96). New York: Routledge.

25. Vizer, E. A. (2007). Movimentos sociais: novas tecnologias para novas militâncias. En J. Ferreira \& E. A. Vizer (Orgs.), Mídia e movimentos sociais: linguagens e coletivos em ação (pp. 23-52). São Paulo: Paulus.

26. Wray, S. (1998). Electronic civil disobedience and the world wide web of hacktivism: a mapping of extraparliamentarian direct action net politics. Switch New Media Journal, 4(2). Recuperado de https://goo.gl/ JxKHSO 